\title{
Ecologic or Community Based Study
}

National Cancer Institute

\section{Source}

National Cancer Institute. Ecologic or Community Based Study. NCI Thesaurus. Code C127780.

A type of clinical study in which geographically distinct study populations are compared with respect to a particular outcome. 